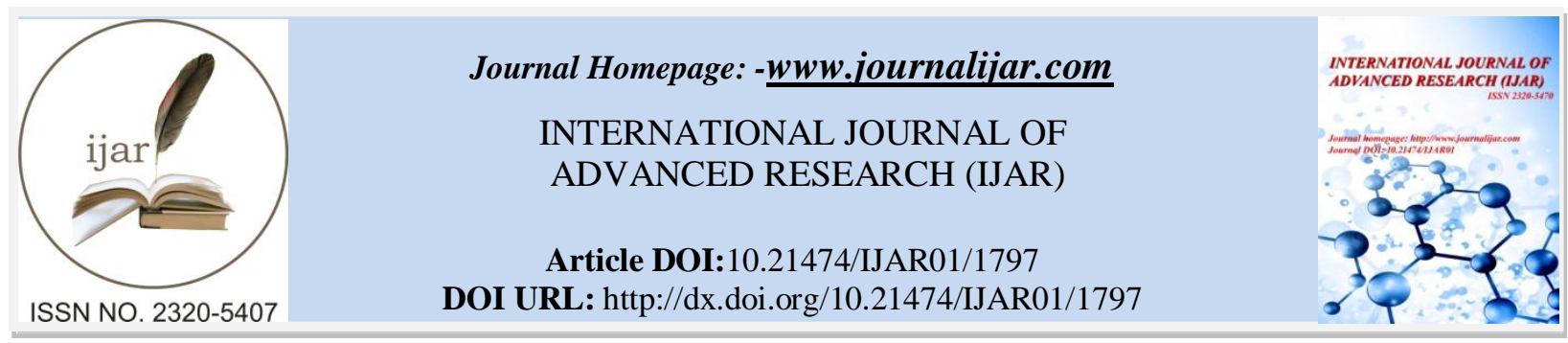

RESEARCH ARTICLE

\title{
FACTOR THAT MAY BE A GAME CHANGER AND MUST BE ADDRESSED NOW: SELF-DRIVING CARS AND AUTONOMOUS-DRIVING VEHICLES DEPLOYMENT.
}

Maria Angelica Deeb (PE, MS, MEP, MPA) (2016)

City of Mesa Transportation Department.

\section{Manuscript Info}

Manuscript History

Received: 12 August 2016

Final Accepted: 22 September 2016

Published: October 2016

Keywords:-

self driving cars, automated vehicles; transportation, public policy, mobility, travel options,

\section{Abstract}

This paper summarizes the forecast made by others on when automated and self-driving cars are going to be available, and when will they be common on the roads. Based on current forecasts, it is concluded that accommodations to construction and operation of roads and cities will not have to be done at this time, however this is the time to develop strategies to enhance positive outcomes and mitigate negative impacts the automated and self-driving cars may pose. Now is the time to think of the implications, impacts, benefits and costs, and the potential strategic physical and policy options. Autonomous vehicles and self-driving cars are going to be part of the road users' transportation professionals are going to have to deal with. Now is the time to plan for accommodations that may need to be implemented to the road catering to users that will not have these autonomous vehicle vehicles but will conflict and interact with those that do. Research suggests that autonomous vehicles will probably increase total vehicle travel unless implemented with offsetting policies such as efficient road and parking pricing. Another critical issue is the degree of potential benefits that can be achieved when only a portion of vehicle travel is autonomous. A key public policy issue is the determination of the degree that this technology may harm people who do not use such vehicles. For now, transportation professionals must get involved in making sure that autonomous vehicles do not create negative impacts to roadway users using or not using self-driving technology. Public Policy makers must plan ahead on how to accommodate self-driving cars. Encouragement from transportation and city government professional is needed, and they must look at ways to create public policy measures that encourage benefits to the cities when self-driving cars are introduced to the market. Benefits can vary, but are not limited to reduction in the need for parking, encouragement of intermodal trips, and expansion of mobility by providing lower-cost travel options. Public policy can encourage the development of new mobility options that are obtained through self-driving cars. 


\section{Introduction:-}

It is a fact that self-driving cars are going to alter how people get around cities. Such driving is going to change the ways cities work and this is going to affect Arizona cities. On August 12, 2016, the Arizona Department of Transportation held the first meeting of the Self-Driving Vehicle oversight committee which was opened to the public. To what degree the cities will have to change is a matter of continuous discussions. In June 2015, Yonah Freemark discussed this same issue in his article posted in the Transport Politic titled: Will autonomous cars change the role and value of public transportation? (Freemark 2015) He states that autonomous vehicles will affect transportation systems and cities as "they may alter the types of public transportation regions provided to citizens and they may increase or decrease the amount of driving people do." It is time, he concludes, to start the conversation of how to handle such driving as this is going to "impact the urban environment and will imply the need for public policy" to address questions of space, access and decisions to be made of how public transportation systems will work in the not so far future.

\section{Background:-}

There is also a question for city government on how these autonomous cars will be introduced. No one knows if these will simply replace today's Uber drivers, or will they be owned by private individuals. The International Transport Forum (ITF) has modeled scenarios showing increases in traveled miles with the rollout of self-driving vehicles and they entertain the idea that individuals that own self-driving cars may order their vehicles to drop them off in front of stores or other destination points, and have their car circle the block for hours while shopping. Other scenarios alternatively, have autonomous cars been publically and/or cooperatively owned, thus providing a service to many and this could have significant benefits for cities by reducing the need for parking, encouraging intermodal trips, and expanding mobility by providing lower-cost travel options. Inorder to assess the impact of these, it must be understood what are the levels of autonomous vehicles currently been discussed. The table below was provided by NHTSA 2013:

Table 1:- Levels of Autonomous Vehicles.

Levels of Autonomous Vehicles (NHTSA 2013)

Level 1 - Function-specific Automation: Automation of specific control functions, such as cruise control, lane guidance and automated parallel parking. Drivers are fully engaged and responsible for overall vehicle control (hands on the steering wheel and foot on the pedal at all times).

Level 2 - Combined Function Automation: Automation of multiple and integrated control functions, such as adaptive cruise control with lane centering. Drivers are responsible for monitoring the roadway and are expected to be available for control at all times, but under certain conditions can disengaged from vehicle operation (hands off the steering wheel and foot off pedal simultaneously).

Level 3 - Limited Self-Driving Automation: Drivers can cede all safety-critical functions under certain conditions and rely on the vehicle to monitor for changes in those conditions that will require transition back to driver control. Drivers are not expected to constantly monitor the roadway.

Level 4 - Full Self-Driving Automation: Vehicles can perform all driving functions and monitor roadway conditions for an entire trip, and so may operate with occupants who cannot drive and without human occupants.

NHTSA (2013), Preliminary Statement of Policy Concerning Automated Vehicles, National Highway Traffic Safety Administration (www.nhtsa.gov)

If the trend continues, the new mobility options created by cooperative autonomous vehicle driving will complement positively existing transportation systems. Yonah states that according to statistics from the American Public Transportation Association, ridership on buses and trains operated by major transit operators in the San Francisco area - BART, San Francisco Muni, Oakland's AC Transit and Caltrans, increased between 2013 and 2014, although in 2013 Uber was already providing approximately 160,000 trips per week in the Bay Area.

\section{Forecasts and Trends:-}

We can assume that the technology and safety features needed for autonomous vehicles will take at least the minimum time other vehicle safety measures took to be available and part of the car-markets within the US and 
world-wide. It is assumed that it may take 15 or up to 50 years for technology to be available for Level 4 to be a remote possibility and available to most car users and at a reasonable cost. Table 2 below lists the deployment cycles, typical premium costs and market saturation share of some know and available automobile safety technology. The summary is used as an indicator of the deployment cycle, costs and market share for autonomous driving technologies.

Table 2:- Vehicle Features - Deployment Summary.

\begin{tabular}{|c|c|c|c|}
\hline Name & Deployment Cycle & Typical Cost Premium & Market Saturation Share \\
\hline Air bags & 25 years $(1973-98)$ & A few hundred dollars & $100 \%$, due to federal mandate \\
\hline Automatic transmissions & 50 years $(1940 s-90 s)$ & $\$ 1,500$ & $90 \%$ U.S., $50 \%$ worldwide \\
\hline Navigation systems & $30+$ years $(1985-2015+)$ & $\$ 500$ and rapidly declining & Uncertain; probably over $80 \%$. \\
\hline Optional GPS services & 15 years & $\$ 250$ annual & $2-5 \%$ \\
\hline Hybrid vehicles & $25+$ years (1990s-2015+) & $\$ 5,000$ & Uncertain. Currently about $4 \%$. \\
\hline
\end{tabular}

New technologies usually require several decades between commercial availability to market saturation.

Todd Litman (2015), “Autonomous Vehicle Implementation Predictions: Implications for Transport Planning", Victoria Transport Policy Institute, 10 December 2015

Most vehicles are durable and median operating lives have average lifespans of 20 years or longer (ORNL 2012). Autonomous driving capability will most likely increase the price of vehicle purchases and may require that users subscribe to special navigation and mapping services. The table below summarizes autonomous vehicle implementation projections. Box 1 provides a prediction timeline of when and what will be available in terms of self-driving and autonomous vehicles.

Table 3:- Autonomous Vehicle Implementation.

\begin{tabular}{|l|r|r|r|r|}
\hline \multicolumn{1}{|c|}{ Stage } & \multicolumn{1}{|c|}{ Decade } & Vehicle Sales & Veh. Fleet & Veh. Travel \\
\hline Available with large price premium & $2020 \mathrm{~s}$ & $2-5 \%$ & $1-2 \%$ & $1-4 \%$ \\
\hline Available with moderate price premium & $2030 \mathrm{~s}$ & $20-40 \%$ & $10-20 \%$ & $10-30 \%$ \\
\hline Available with minimal price premium & $2040 \mathrm{~s}$ & $40-60 \%$ & $20-40 \%$ & $30-50 \%$ \\
\hline Standard feature included on most new vehicles & $2050 \mathrm{~s}$ & $80-100 \%$ & $40-60 \%$ & $50-80 \%$ \\
\hline Saturation (everybody who wants it has it) & $2060 \mathrm{~s}$ & $?$ & $?$ & $?$ \\
\hline Required for all new and operating vehicles & $? ? ?$ & $100 \%$ & $100 \%$ & $100 \%$ \\
\hline
\end{tabular}

Autonomous vehicle implementation will probably take several decades.

Todd Litman (2015), “Autonomous Vehicle Implementation Predictions: Implications for Transport Planning”, Victoria Transport Policy Institute, 10 December 2015

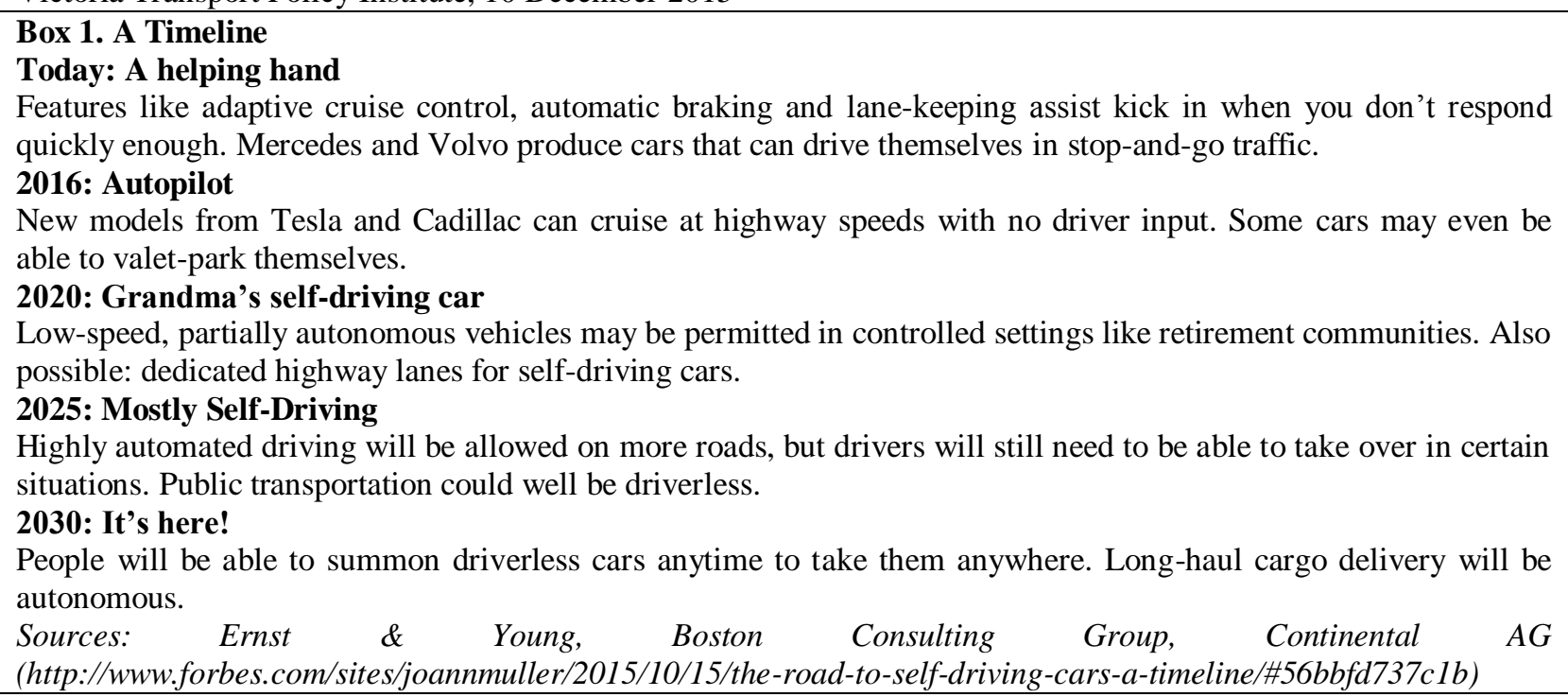


Forecasts made in early 2016 by Volkswagen, GM, BMW, Ford (and these are available to the public at Driverless car market watch), predict that the first self-driving cars may be available in the market by 2019-2021 (Exhibit 1). Figure 1 was obtained from Victoria Transport Policy Institute's Autonomous Vehicle Implementation Predictions (Litman 2015) that concludes that in the 2040's autonomous vehicles will represent approximately 50\% of vehicle sales, $30 \%$ of vehicles, and $40 \%$ of all vehicle travel. Only in the 2050s would most vehicles be capable of automated driving.

Figure 1:- Autonomous Vehicle Sales, Fleet and Travel Projections.

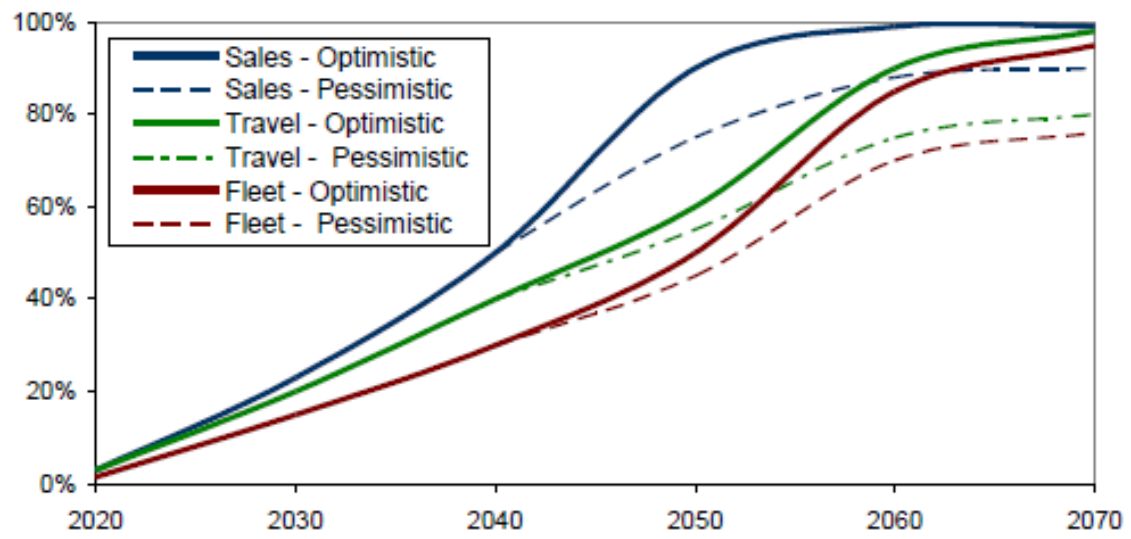

If autonomous vehicle implementation follows the patterns of other vehicle technologies it will take one to three decades to dominate vehicle sales, plus one or two more decades to dominate vehicle travel, and even at market saturation it is possible that a significant portion of vehicles and vehicle travel will continue to be self-driven, indicated by the dashed lines.

Todd Litman (2015), "Autonomous Vehicle Implementation Predictions: Implications for Transport Planning", Victoria Transport Policy Institute, 10 December 2015

\section{Benefits and Costs:-}

The Transportation Research Board has stated that computer piloted vehicles will reshape how states and localities build, manage and govern their roads. Daniel C. Vock in his article: "7 ways self-driving cars could impact states and localities" introduces the concept that the market will need to improve the technology that will be used, and its currently been used in automated vehicles. Although improving technology is one of the impacts that is now been felt, it is hardly a cause or effect of self-driving cars. However, it is true that these vehicles need cameras or GPS maps to effectively keep from conflicting with on-coming traffic and may be that the specific items that are been considered and are available in the cameras or GPS technology cater to such vehicle type. The vehicles also use technology such as ruble strips along the center line and road shoulders to demarcate their route. Vock quotes David Agnew, a researcher for an auto parts manufacturer, Continental Automotive Systems, who states that an accelerometer in a car can easily detect the vibration from the rumble strips and correct course.

Robin Chase wrote an article in CityLab were she concludes that automated cars will dramatically change the equation for public transit service because of the "much cheaper prices made possible when there's no human labor involved." For Chase, "buses, shuttles, minivans, school buses [will be] all gone" because these low-capacity transit modes will be replaced by automated cooperative cars which are not limited to their utility in fixed schedules and that may adapt to point-to-point demand. This is interesting as it raises a scenario that will require a significant public policy role through subsidies if cities are to maintain mobility for low-income people who do not have access to their own cooperative self-driving pool of cars. This service mirrors the existing Paratransit services of today; "paratransit trips costs the public purse more than three times as much to provide as regular bus and rail services according to the U.S. Government Accountability Office, but that's in part because of the low capacity of paratransit vehicles, high labor costs, and their non-fixed route services" (Chase 2014).

Paratransit has been implemented as a result of the federal government mandate, which extends from the American with Disabilities Act. So, how will cities change their transportation infrastructure (less parking, better demarcation in their streets with changes stripping, markings and signs), their public policies (such as the provision of paratransit 
services) and how will cities invest in public transportation? It is the time to search for the answers to these questions.

Another impact that is currently been discussed within cities and localities is that of standardization. When selfdriving vehicles become more common, signs, signals and roadways will most likely need to include standards so that self-driving vehicles can navigate safely and not be constrained to a corridor, city or region. According to Agnew, "the differences in signs used by different states in the United States is greater than the variety of those used by different countries in Europe." Self-driving vehicle manufactures have to rustle with developing a car that operates well, effectively and in most places even though there is not universal standard. To what degree should non-standardization be accommodated? Will this affect the cost and reliability of the vehicle? These are just two questions that still need to be answered by government and the self-driving developers and its market.

Vock further states that private businesses and technology developers fear that regulations imposed by public officials will limit, increase the cost, or stop to a crawl, improvements made by them. But when it comes to driverless cars, California's Transportation Director Malcolm Dougherty found the opposite to be true. Dougherty stated that the state issued regulations for autonomous vehicles and these regulations allowed researchers to operate lawfully and safely on state roads while experimenting with new technology.

Another impact that is currently in the mind of all public officials and city budget managers is the cost of thetransportation infrastructure if its life cycle is shortened. Transportation departments build roads and transportation infrastructure that lasts for 15 to 50 years. Technology such as smartphones and computers advances so fast that it's generally considered obsolete after two years. In some cases, cell phone providers entice their customers to change their cell phone every 12 to 24 months; and the customer does not always own the technology they pay to access and use. John Barton, Deputy Executive Director of the Texas Department of Transportation, is aware of this fact, and chooses to pay a in a yearly basis access to the web for technologies and software's such as Microsoft Office that allows vehicles and infrastructure to communicate to each other. According to Barton, "In fact, a private provider may also be willing to collect, process and analyze huge amounts of information gathered by those systems for the state for free, if they are able to also use it for their own commercial purposes."

Yet, another impact worth discussing is that of cybersecurity and privacy definition/expectation. Although public officials in general state to the public that transportation systems and the government's that oversee them do not track personal information and do not share personal location information outside of the government system, people are wary of vehicle systems that keep track of their movements. But the fear extends to how autonomous systems implementation may be hacked and may be used for criminal or terrorist activity.

\section{Planning:-}

In 2016, new vehicles have some Level 1 automation features such as cruise control, obstruction warning, and parallel parking. In 2017-2021, car manufacturers plan to offer Level 2 features such as automated lane guidance, accident avoidance, and driver fatigue detection. Google Level 3 test vehicles have reportedly driven hundreds of thousands of miles under restricted conditions: specially mapped routes, fair weather, and human drivers able to intervene when needed (Muller 2013).

Some manufacturers forecast having Level 4 automation vehicles sometime in the early 2020s but this is uncertain. Many forecast that when Level 4 is achieved the early versions of autonomous vehicles will probably be limited to "controlled" environments such as freeways (Row 2013). Failure could be deadly to vehicle occupants and other road users; therefore, automated driving has high performance requirements. Sensors, computers and software must be robust, redundant and resistant to abuse. Several more years of development and testing will be required before regulators and potential users gain confidence that Level 4 vehicles can operate as expected under all conditions (Bilger 2013; Schoettle and Sivak 2015).

Even if we assume that fully-autonomous vehicles will be available for sale and legal to drive on public roads around 2020, one may predict, that early versions are initially imperfect, with questionable reliability and performance, and are costly; therefore "they represent a small portion of total vehicle sales, with market share increasing during subsequent decades as their performance improves, prices decline, and their benefits are demonstrated (Litman 2015).” 
The table below summarizes the potential impacts (benefits and costs) of autonomous vehicles, noting that these may provide various possible outcomes and it is time for government, city, and transportation planners to take note.

Table 4:- Benefit and Costs of Autonomous Vehicles.

\begin{tabular}{|c|c|}
\hline Benefits & ems \\
\hline $\begin{array}{l}\text { Reduced driver stress. Reduce the stress of driving and } \\
\text { allow motorists to rest and work while traveling. } \\
\text { Reduced driver costs. Reduce costs of paid drivers for } \\
\text { taxis and commercial transport. } \\
\text { Mobility for non-drivers. Provide independent mobility for } \\
\text { non-drivers, and therefore reduce the need for motorists } \\
\text { to chauffeur non-drivers, and to subsidize public transit. } \\
\text { Increased safety. May reduce many common accident } \\
\text { risks and therefore crash costs and insurance premiums. } \\
\text { May reduce high-risk driving, such as when impaired. } \\
\text { Increased road capacity, reduced costs. May allow } \\
\text { platooning (vehicle groups traveling close together), } \\
\text { narrower lanes, and reduced intersection stops, reducing } \\
\text { congestion and roadway costs. } \\
\text { More efficient parking, reduced costs. Can drop off } \\
\text { passengers and find a parking space, increasing motorist } \\
\text { convenience and reducing total parking costs. } \\
\text { Increase fuel efficiency and reduce pollution. May } \\
\text { increase fuel efficiency and reduce pollution emissions. } \\
\text { Supports shared vehicles. Could facilitate carsharing } \\
\text { (vehicle rental services that substitute for personal } \\
\text { vehicle ownership), which can provide various savings. }\end{array}$ & $\begin{array}{l}\text { Increases costs. Requires additional vehicle equipment, } \\
\text { services and maintenance, and possibly roadway } \\
\text { infrastructure. } \\
\text { Additional risks. May introduce new risks, such as system } \\
\text { failures, be less safe under certain conditions, and encourage } \\
\text { road users to take additional risks (offsetting behavior). } \\
\text { Security and Privacy concerns. May be used for criminal and } \\
\text { terrorist activities (such as bomb delivery), vulnerable to } \\
\text { information abuse (hacking), and features such as GPS } \\
\text { tracking and data sharing may raise privacy concerns. } \\
\text { Induced vehicle travel and increased external costs. By } \\
\text { increasing travel convenience and affordability, autonomous } \\
\text { vehicles may induce additional vehicle travel, increasing } \\
\text { external costs of parking, crashes and pollution. } \\
\text { Social equity concerns. May have unfair impacts, for example, } \\
\text { by reducing other modes' convenience and safety. } \\
\text { Reduced employment and business activity. Jobs for drivers } \\
\text { should decline, and there may be less demand for vehicle } \\
\text { repairs due to reduced crash rates. } \\
\text { Misplaced planning emphasis. Focusing on autonomous } \\
\text { vehicle solutions may discourage communities from } \\
\text { implementing conventional but cost-effective transport } \\
\text { projects such as pedestrian and transit improvements, pricing } \\
\text { reforms and other demand management strategies. }\end{array}$ \\
\hline
\end{tabular}

Autonomous vehicles can provide various benefits and impose various costs.

Todd Litman (2015), “Autonomous Vehicle Implementation Predictions: Implications for Transport Planning", Victoria Transport Policy Institute, 10 December 2015

Autonomous vehicle implementation is just one of the factors that may affect future transport demands and costs. Factors like: demographic trends, changing consumer preferences, price changes, improved transport options, improved user information, and other innovations may influence the way and how much people drive. The combination of all the factors listed above may have greaterplanning impacts than the impacts resulting from autonomous vehicles, at least until the 2040s.

\section{Functional requirements and planning implications:-}

The projections suggest that during the 2020s and 30s transport planners and engineers will primarily be concerned with defining autonomous vehicle performance, testing and reporting requirements for operation on public roadways. During the 2030s or 40s it may be observed that autonomous vehicles will be utilized as taxi and carsharing services, therefore reducing the need for conventional public transit services and providing more households to use these services and reduce their vehicle ownership, which could reduce parking requirements. However, modeling by the International Transport Forum indicates that self-driving taxis and public transit services are complements rather than substitutes, since transit is more efficient at serving many peak-period urban trips and so significantly reduces the self-driving taxi fleet size and costs.

When autonomous vehicles become a major share of total vehicle travel, these type of vehicles may significantly reduce traffic risk, traffic congestion, parking problems, and provide some energy savings and emission reductions. However, in order to experience these benefits, autonomous vehicles must be the major share or vehicles in public 
roadways. Planners have expressed safety concerns for those vehicle users who do not have autonomous features within their vehicles, or other road users such as pedestrians and bicyclists. Planners must think, now, of these nonautonomous vehicle users.

\section{Conclusion:-}

Autonomous vehicles and self-driving cars are going to be part of the road users, we as transportation professionals are going to have to accommodate. Now is the time to plan for the road users who do not have autonomous vehicles but will conflict and interact with those who do. A critical question is whether autonomous vehicles will increase or reduce total vehicle travel and associated external costs. The truth is that we do not know, and the answer may depend on the market, region, and technology availability.

Research suggests that they will probably increase total vehicle travel unless implemented with offsetting policies such as efficient road and parking pricing. Another critical issue is the degree potential benefits can be achieved when only a portion of vehicle travel is autonomous. A key public policy issue is the degree that this technology may harm people who do not use such vehicles. Will the market make cities evolve to situations where there are increased traffic volumes and speeds and a degraded walking and cycling conditions, conventional public transit service declines, or human-driven vehicles are restricted?

For now, transportation professionals must get involved in making sure that autonomous vehicles do not create negative impacts to roadway users utilizing or not self-driving technology. But, we also have to plan ahead on how to accommodate self-driving cars. I conclude that policy debates concerning whether public policies should encourage or require autonomous vehicles will happen soon.

I encourage transportation and city government professionals to look at ways to create public policy measures that encourage benefits to the cities when self-driving cars are introduced to the market. Benefits can vary, but are not limited to reduction in the need for parking, encouragement of intermodal trips, and expansion of mobility by providing lower-cost travel options. Public policy can encourage the development of new mobility options that are obtained through self-driving cars. Some of the research states that self-driving cars are to change the equation for public transit significantly, but this will only happen if public policy administrators take the role, now, to study effective and efficient ways of developing subsidy programs that increase the potential benefit.

It is the time, now, for cities to determine strategies for funding methods to gather data that will allow them to monitor self-driving technologies and their effect in their US, region and city/town. The analysis of the data will allow cities to determine the need to change their transportation infrastructure (less parking, better demarcation in their streets with changes stripping, markings and signs), the need for creating public policies (such as the provision of paratransit services) and establish investment programs in public transportation. Autonomous vehicle implementation is just one of the factors that may affect future transport demands and costs, but it is certainly a key factor that needs to be addressed now.

These benefits and impacts of autonomous and self-driving cars may vary geographically, with more rapid implementation in areas that are more affluent and more congested that Arizona cities. Autonomous vehicle implementation is just one of many trends likely to affect future transport demands and costs. Its ultimate impacts depend on how it interacts with other trends, such as views regarding vehicle ownership and car-pool/sharing vehicles. Autonomous vehicles will not re-define how transport problems are viewed; rather, it reinforces existing automobile-oriented transport planning. 


\title{
Forecasts
}

\section{Exhibit 1 - Forecasts:-}

\author{
Autonomous car forecasts \\ This page lists the most recent predictions about when driverless cars will be available on the \\ market: \\ Volkswagen expects first self driving cars on the market by 2019 \\ Johann Jungwirth, Volkswagen's appointed head of Digitalization Strategy, expects the first self- \\ driving cars to appear on the market by 2019 . He did not claim that these would be Volkswagen \\ models. \\ (Source: Focus, 2016-04-23) \\ GM: Autononomous cars could be deployed by 2020 or sooner \\ General Motor's head of foresight and trends Richard Holman said at a confererence in Detroit \\ that most industry participants now think that self-driving cars will be on the road by 2020 or \\ sooner. \\ Source: Wall Street Journal, 2016-05-10 \\ BMW to launch autonomous iNext in 2021 \\ At their annual shareholder meeting, BMW CEO Harald Krueger said that BMW will launch a self- \\ driving electric vehicle, the BMW iNext, in 2021. \\ Source: Elektrek, 2016-05-12 \\ Ford's head of product development: autonomous vehicle on the market by $\mathbf{2 0 2 0}$ \\ Raj Nair, Ford's head of product development, expects that autonomous vehicles of SAE level 4 \\ (which means that the car needs no driver but may not be capable of driving everywhere) will hit \\ the market by 2020.(Source: autonews, 2016-02-27)
}

Driverless Car Market Watch, Gearing up to save lives, reduce costs, resource consumption at http://www.driverless-future.com/?page_id=384

\section{Bibliography:-}

1. NHTSA (2013), Preliminary Statement of Policy Concerning Automated Vehicles, National Highway Traffic Safety Administration (www.nhtsa.gov).

2. Yonah Freemark (2015), "Will autonomous cars change the role and value of public transportation?", Transport Politic, 23 June 2015; at http://www.thetransportpolitic.com/2015/06/23/will-autonomous-cars-change-the-roleand-value-of-public-transportation/.

3. Robin Chase (2014), "Will a World of Driverless Cars Be Heaven or Hell?", CityLab, 3 April 2014; at http://www.citylab.com/commute/2014/04/will-world-driverless-cars-be-heaven-or-hell/8784/.

4. Daniel C. Vock, "7 Ways Self-Driving Cars Could Impact States and Localities”, Governing, 15 January 2015; at http://www.governing.com/topics/transportation-infrastructure/gov-driverless-cars-impact-stateslocalities.html.

5. Todd Litman (2015), “Autonomous Vehicle Implementation Predictions: Implications for Transport Planning”, Victoria Transport Policy Institute, 10 December 2015; presented at the 2015 Transportation Research Board Annual Meeting (www.trb.org), 15-3326. Summarized in "Ready or Waiting," Traffic Technology International, January 2014, pp. 36-42.

6. Joann Muller (2013), "No Hands, No Feet: My Unnerving Ride In Google's Driverless Car," Forbes Magazine (www.forbes.com), 21 March 2013; at www.forbes.com/sites/joannmuller/2013/03/21/no-hands-no-feetmyunnerving-ride-in-googles-driverless-car.

7. Shelley Row (2013), "The Future of Transportation: Connected Vehicles to Driverless Vehicles...What Does It Mean To Me?” ITE Journal (www.ite.org), Vol. 83, No. 10, pp. 24-25.

8. Brandon Schoettle and Michael Sivak (2015), Should We Require Licensing Tests And Graduated Licensing For Self-Driving Vehicles?, Report UMTRI-2015-33, Transportation Research Institute, University of Michigan (www.umich.edu/ umtriswt). 